\title{
Black-White Wage Inequality in the 1990s: A Decade of Progress
}

\author{
Kenneth Couch \\ Department of Economics \\ University of Connecticut \\ 341 Mansfield Road \\ Storrs, CT 06269 \\ (860) 486-4570 \\ kcouch@uconnvm.uconn.edu \\ Mary C. Daly \\ Economic Research Department \\ Federal Reserve Bank of San Francisco \\ 101 Market Street, Mail Stop 1130 \\ San Francisco, CA 94105 \\ Ph: (415) 974-3186 \\ Fax: (415) 977-4054 \\ mary.daly@sf.frb.org
}

August 2000

*We thank Frederick Furlong and seminar participants at the 2000 Winter Meetings of the Econometric Society, and the 2000 EALE/SOLE World Conference for helpful comments. We also thank Judy Peng and Carol D'Souza for research support and Anita Todd for editorial assistance. None of these individuals are responsible for any errors. Part of this work was completed while Kenneth Couch was a Visiting Scholar at the Federal Reserve Bank of San Francisco. The views expressed in this paper are those of the authors and should not be attributed to the Federal Reserve Bank of San Francisco or the Federal Reserve System. 


\title{
Black-White Wage Inequality in the 1990s: \\ A Decade of Progress
}

\begin{abstract}
Using Current Population Survey data, we find that the gap between wages by black and white males declined during the 1990 s at a rate of 0.59 percentage point per year. The reduction in occupational crowding appears to be most important in explaining this trend. Recent wage convergence was most rapid among younger workers with less than 10 years experience; for this group the black-white wage gap declined by 1.40 percentage points per year. Among younger workers greater occupational diversity and a reduction in unexplained or residual differences are important in explaining this trend. For both younger and older workers, general wage inequality tempered the rate of wage convergence between blacks and whites during the 1990s.
\end{abstract}




\section{Black-White Wage Inequality in the 1990s: \\ A Decade of Progress}

\section{Introduction}

Following the passage of the Civil Rights Act of 1964 and other measures aimed at reducing labor market discrimination during the 1960s, the differential in average weekly wages between black and white men in the United States narrowed substantially. Among male workers aged 18-64, the black-white wage gap fell from 50 percent in 1967 to 30 percent in 1974, or by about one percent per year. ${ }^{1}$ After 1974 , however, the proportional difference in black and white wages remained essentially constant at 30 percent through the end of the 1980s. Following more than a decade of stasis, the black-white wage gap once again began to decline during the 1990s, narrowing at a rate approaching one percent a year.

A great deal of past research has focused on why the black-white wage gap did not continue to decline following the initial progress made through the mid-1970s. One of the earliest studies in this area (Juhn, Murphy, and Pierce 1991) concluded that a key factor undermining progress towards wage convergence between blacks and whites during the 1980s was a broader trend of rising wage inequality in American society. The authors found that growing disparity in returns-to-skill combined with disproportionate representation of blacks in the lower end of the skill distribution combined to hold down growth in the average weekly earnings of blacks relative to whites during the 1980s. According

1 The figures cited in this paragraph are based on calculations presented and explained later in the text. 
to Juhn, et al., the damping effect of societal inequality on the wage gap during the decade of the 1980s was sufficient to offset gains made by blacks along other dimensions, such as acquisition of schooling.

This paper documents the recent progress in black-white wage convergence and following Juhn, et al. (1991) considers the role of overall societal income inequality, sectoral employment, and individual characteristics in reducing the racial gap in earnings during the decade of the 1990s. We initially replicate the findings of Juhn et al. using Current Population Survey (CPS) data and then move on to document important changes in the trend of the black-white wage gap which have occurred since 1990. In future research, we hope to revisit the issue of educational quality and individual skills and their role in this context using other data. ${ }^{2}$

\section{Data}

The CPS data we employ in the analysis has well-known advantages and disadvantages. The primary advantage of these data is that they are designed to obtain accurate national measures of labor market outcomes. The primary disadvantage in this context is that the measures of direct skills available in the survey are limited to constructed measures of experience and years of completed education. ${ }^{3}$

We use information from the 1968-1998 March CPS to obtain three decades of data representative of the years 1967 through 1997. The March CPS demographic supplement contains retrospective

There is a large literature on the role of education and school quality on the evolution of the black-white wage gap; see Card and Krueger (1992a, 1992b), Grogger (1996), and Maxwell (194) for examples. However, given the limitations of the CPS data, our analysis will not address these issues.

3 Relative to other data sets such as the High School and Beyond (HSB), the CPS does not survey respondents in a detailed fashion regarding their educational experiences or contain standardized test outcomes. Therefore, information is not available to extensively investigate the role of changes in educational quality on the wage gap. 
earnings information collected for the previous year.

Since we are primarily interested in long-term trends in wages rather than changes in earnings volatility associated with entry and exit from the labor market, we impose a number of sample restrictions. We include black and white male workers ages 18-64 who worked at least one week in the previous calendar year, usually worked full-time, and participated in the labor force for at least thirty-nine weeks. To avoid problems associated with top-coding, we exclude individuals in the top and bottom one percent of the earnings distribution. Throughout the paper we focus on the average weekly wage, calculated as the annual wage divided by the number of weeks worked. The annual earnings measures are deflated using the personal consumption expenditure deflator from the National Income and Product Accounts. We refer to the log of the deflated average weekly wage as the wage.

In the initial analysis we focus on the log weekly wage adjusted for potential experience, where potential experience is calculated as the lesser of age minus education minus seven, and age minus 17. Later in the paper, we investigate the role of differential employment by industry and occupation as a source of racial earnings inequality. To do so, we construct a set of indicator variables for two-digit industry of employment and the major occupational group of each individual's job. In all cases the variable definitions and the sample selection criteria we employ are similar to those employed in Juhn, Murphy, and Pierce 1991.

\section{Trends in the Black-White Wage Gap}

We first consider black-white log wage ratios for the years from 1967 through 1997 for two groups, all male workers and male workers with 10 or fewer years of potential experience. Like previous researchers, we find that among all workers, the black-white gap in earnings declined sharply 
from the late 1960s through the mid-1970s (Figure 1). Similarly, we find little wage convergence between blacks and whites from the mid-1970s through the end of the 1980s (the period examined most recently by other researchers). Since the end of the recession in 1991, however, there have been three observations of the unadjusted wage gap which were less than $.30(.27, .29$, and .27). Historically, those are the lowest wage gaps observed for black and white males. While these are modest reductions for minority workers as a whole, they nonetheless represent progress in wage convergence after two decades of stagnation.

One possible explanation for the recent decline in wage differentials between blacks and whites is simply that older cohorts of less-educated blacks are being replaced by younger, better educated black workers. To get a sense of the role that cohort effects have played in the recent improvement in the black-white wage gap, Figure 1 also shows the unadjusted differential for those with less than 10 years of experience. Again, a pattern of fairly rapid narrowing of the black-white wage gap among these workers from the late 1960s through the mid-1970s is observed. This pattern reverses during the 1980s, when the unadjusted wage gap actually increases. Looking at the 1990s, however, reveals new black workers gaining on their white counterparts. Between 1989 and 1997, there are three instances of historical lows for the unadjusted wage gap among workers with less than ten years of experience $(.20, .12$, and .18).

Table 1 provides a more detailed analysis of the evolution of the black-white wage gap by years of potential labor market experience. The wage gaps reported in the table represent averages over five-year intervals of the CPS data. Although other observations might be drawn from the table, we focus on two issues: (1) How has the wage gap varied over time for different levels of experience? 
(2) How have different cohorts faired? The answers to these questions are important for interpreting the meaning of the recent wage convergence. For example, if we find that the recent wage convergence is entirely attributable to the entry of younger cohorts of more highly educated workers, it would suggest that the narrowing wage gap is skill-related. On the other hand, if the wage convergence is observed as given cohorts move through time, this would suggest that some of the convergence is due to a lessening of discrimination towards all groups.

Looking across the rows of Table 1, it is apparent that in historical perspective, the unadjusted black-white wage gap among workers of all skill levels has declined markedly. For all workers, the decline from .44 in the interval from 1968 through 1972 to .31 in the period from 1993 through 1997 represents a decrease of 30 percent. For the different skill levels in the table, the reductions in wage inequality range from one-third to two-thirds depending on the particular group examined.

In contrast, by examining the diagonals of the table, one may follow different cohorts over time as they age and acquire additional years of potential experience. For example, the group of minority workers who had less than six years of potential experience in the 1968-1972 interval experienced a wage gap of 36 percent. By the time of the 93-97 interval, when their potential experience ranged from 26 to 30 years, the wage gap they experienced had fallen to 31 percent, a reduction of 14 percent.

The evidence provided in Table 1 suggests that recent black entrants to the labor market are either better educated or more skilled than older workers as their wage convergence is the greatest among all skill levels. It is also apparent that the returns to the types of skills offered by blacks in the labor market appear to have risen in value over time and that this is most apparent among the youngest workers. Thus, there is an overall pattern of convergence independent of age and experience, but 
those experiencing the greatest convergence are the most recent entrants to the labor market. This preliminary evidence suggests that either an increase in skills among blacks relative to whites or a higher rate of return for the skills offered by blacks relative to those offered by whites is likely to be important in explaining convergence in the wage gap. The evidence in Table 1 also suggests that either discrimination or racial differences in other dimensions such as their occupation have been decreasing over time.

\section{Wages and Observable Characteristics}

\section{A. Education}

One measure of skill is completed years of education. It has been long established that higher levels of education are associated with greater earnings. Recent research has shown that the premium earned by those with more education has grown dramatically during the past 15 years. While returns to education have risen for all workers, recent entrants to the labor market have experienced the most dramatic increases (Juhn et al. 1993). Figure 2 shows the trends in the log wage ratio for college educated and non-college educated workers. As can be seen in the figure, the returns to education among all workers have been rising steadily since the mid 1980s. The college wage premium is highest for workers with less than ten years of experience.

To the extent that blacks have become more highly educated over time, perhaps due to a lessening of premarket discrimination in the educational system, their wages should converge with those of whites and vice versa. Table 2 provides information on the distribution of educational levels for black and white workers in our sample across four categories: less than high school, high school graduates, some college, and college graduates. This information is broken out for blacks and whites 
into groups of all workers and workers with no more than 10 years of experience.

There are a number of striking trends in these tables. First, there has been an enormous reduction in the past 30 years in the proportion of American workers, black and white, who have not completed high school. Among all blacks in 1968, 63 percent had not completed high school. By the last year of our sample, 1998, that figure had declined to less than 15 percent, a reduction of 77 percent! A similar reduction occurred among white workers in our sample. In 1968, about 37 percent of all white workers had less than a high school education. By 1998, that figure had declined to 12 percent, which represents a reduction of 68 percent. While the reduction for both groups is remarkable, the trend is more important for blacks because of the relatively larger share that did not previously graduate.

In the last year of our sample, the proportion of whites and blacks with high school degrees or some college are similar. However, whites have more college graduates. This trend holds even among new entrants. As shown in Table 2, relative to all black workers, those with less than ten years of experience in our sample in 1998 have a higher rate of college completion and fewer high school incompletions. However, even among new entrants the rate of college graduation is lower among blacks than among whites. One would expect that some portion of the convergence in the black-white wage gap is connected to improved rates of high school graduation among blacks and the increasing number who pursue college.

\section{B. Employment by Industry and Occupation}

Table 3 shows the evolution of black and white employment by two-digit industry since 1968 . As might be expected, some industries contain larger shares of blacks than whites - personal services, 
public service, and transportation are notable examples. But even in those cases, the proportions of blacks and whites who find employment in specific industries appear fairly similar. Time series variation in employment concentration by industry also is apparent in Table 3. However, in general, the trends are similar for whites and blacks. For example, white employment in manufacturing decreased by 13 percentage points and black employment in manufacturing by 11 percentage points during our sample period. Thus, while changes over time for blacks and whites are not identical, the primary pattern observed in Table 3 appears to be the decline in manufacturing's share of total employment rather than marked differences across racial groups in employment by industry. Similar conclusions can be drawn from the information on less experienced workers contained in Table 3.

Broad industry groupings such as those shown in Table 3 may mask changes in the occupational structure across industries. Table 4 provides information on employment by race and occupation since 1968. What can be seen in Table 4 is that the black and white employment differs by occupation. Blacks are proportionately under represented among professional and managerial occupations. However, over time the proportion of blacks employed in professional and managerial jobs has increased. On the other side of the occupational distribution, the proportion of blacks employed as laborers has decreased over time, while the share of blacks employed as operatives has increased. In more industrial settings, blacks tend to be concentrated in operative rather than craftsmen positions. .

For proportional changes in employment by industry or occupation to play a significant role in explaining movements in wage inequality rates of pay must either differ across occupations and industries or must evolve differently. Figure 3 considers the weekly wage of several industries. Among 
those considered, professional services are characterized by both the highest rates of pay and largest increases over time. In real terms, retail trade has the lowest pay, and wages in that sector have remained essentially flat for the last three decades. Rates of pay across industries clearly differ enough that large shifts in employment would be expected to impact overall wage inequality.

Similarly, Figure 4 considers real weekly wages of several occupations. Blacks had historically worked disproportionately as farm and nonfarm laborers, the two lowest paying occupations shown in the figure. Recently, substantial declines have occurred in their employment as laborers with corresponding increases in operative and craftsmen jobs. Although the rate of increase in pay for those occupations do not appear large, it is clear that the substantial shifts in occupational structure experienced by blacks should raise their wages relative to whites.

\section{Explained and Residual Portions of the Wage Gap}

Even in these basic dimensions, it is difficult to determine which trends are most important in explaining the movement of the relative wages of blacks and whites with descriptive evidence.

However, standard decomposition techniques can be used to identify the portion of the wage gap which is attributable to observable factors and the residual due to other sources in any given year. Here, we follow Juhn, et al. (1991) and estimate an earnings equation each year for white workers of the form:

$$
Y_{i t}{ }^{\prime} \quad X_{i t} \$ \mu_{t} \% \mu_{i t}
$$

where $Y$ represents log weekly wages, $X$ represents observable characteristics, and $\mu$ is a mean zero 
error term. ${ }^{4}$ The difference $(D)$ in white and black log earnings in any year can then be written as:

$$
D_{t}^{\prime} Y_{w t} \& Y_{b t}^{\prime} X_{w t} \$_{t} \&\left(X_{b t} \$_{t} \% \mathrm{~L}_{b t}\right)
$$

or simplifying as:

$$
\left.D_{t}^{\prime} \quad Y_{w t} \& Y_{b t}{ }^{\prime}\right) X_{t} \$_{t} \& \mathrm{~L}_{b t}
$$

where ) $X_{t}=\left(X_{w t}-X_{b t}\right)$. In equation (3), ) $X_{t} \$_{t}$ represents the portion of the wage gap due to observables and $L_{b t}$ represents the residual gap.

We estimate equation (3) for all workers and for workers with less than 10 years of potential experience. Figures 5 and 6 summarize the results of these estimations. ${ }^{5}$ Figure 5 shows the total wage gap as well as the unexplained residual for all male workers. The vertical difference in the two lines in the graph represent how much inequality would be reduced if all observable factors included in the estimations were equalized across blacks and whites. Over the period of the sample, both gaps decline through the mid-1970s and appear to have remained roughly constant through the late 1980s. Since the late 1980s, the trend in both the unadjusted and residual wage gap appears to be slightly downward.

In Figure 6, similar information is shown for those with less than 10 years of potential experience. For these younger workers, the residual component of the wage gap appears to be

${ }^{4}$ The regressors included in the estimations are region of residence, a quartic in potential experience, education, industry, and occupation.

${ }^{5} \mathrm{~A}$ compete set of the underlying results is available from the authors upon request. 
trending downward more strongly since 1990 after trending upwards since the early 1970s, although the series is characterized by considerable noise.

To gain an understanding of whether these trends are statistically meaningful and, if so, their source, we extend equation (3) to account for differences in the wage gap in three periods relative to the average throughout the sample. We use the average throughout the sample to avoid choosing a base year for comparison. We divide our 30-year sample into three time intervals for the analysis, 1968-1979, 1980-1989, and 1990-1998. We estimate the equation

$$
\left.\left.D_{t}, \& \bar{D},\left(\left(X_{t}, \&\right) \bar{X}\right) \Phi \%\right) X_{t},(\$, \& \Phi) \&\left(\mathrm{~L}_{b t}\right) \& \mathrm{~L}_{b}\right)
$$

as a pooled regression over all periods including linear splines to capture the effects in the three subperiods of the sample. The change in the residual gap is represented by $\left(\mathrm{L}_{b t 3} \mathrm{~L}_{b}\right)$. The overall gap is decomposed into three components, the portion due to changes in levels of observable factors () $X_{t 3}$ ) $X) \$$, the portion due to changes in rates of compensation, ) $X_{t 3}(\$ t,-\$)$, and the total residual gap.

The first row of Table 5 shows that in the first ten years of our sample, the total wage gap declined by an average of 1.2 percentage points per year. During the next decade, the wage gap increased by .24 percentage point per year. Since 1990, the overall wage gap has declined by .59 percentage point per year. In explaining the slowdown in convergence in the 1980s, like previous authors, we find that the overall rate of convergence due to observables declined and that the residual gap widened. Within the observable component, the slowdown in the rate of convergence in the 1980s appears to have been associated with declining skill prices.

During the 1990s, the overall trend towards the widening of black-white wage inequality 
observed in the 1980s has been reversed. Racial wage inequality has been declining. This result appears primarily to be attributable to convergence in black and white education levels and industry and occupation of employment.

The effects of education and experience as opposed to sector of employment are also detailed in the paper. One reason to separate the effects of education and experience from the effects of industry and occupation is that the patterns might be interpreted differently with respect to discrimination. If an individual is paid less due to lower education, most economists agree this is not evidence of market discrimination. However, if after controlling for education and experience, blacks are clustered in industries or occupations characterized by lower pay, this may be interpreted as evidence of segregation in employment. In the 1990s, the primary factor among the observable characteristics which appears to be statistically important in explaining the reduction of the wage gap is the convergence in the distributions of employment of blacks and whites during the sample period.

Among workers with less than ten years of labor market experience, the historical pattern of change in the total wage gap is similar to that for all workers. In the period from 1968 through 1979, the wage gap converged at an average of 1.34 percentage points a year. During the decade of the 80 s, the gap widened at .66 percent per year. The rate of convergence during the 1990s has been dramatic, at 1.40 percent per year.

In terms of the factors influencing convergence, much like the larger group of all workers, equalization of the distributions of employment by industry and occupation explains .38 of the 1.40 percentage point per year decline in inequality. The largest factor influencing the reduction in the wage gap, however, is a decline in residual inequality which would account for a 1.21 percentage point 
reduction in the gap since 1990 .

\section{Male Wage Inequality and the Black-White Wage Gap}

The residual black-white wage gap is thought to capture both the effects of labor market discrimination and wage variation associated with unobserved characteristics related to productivity. However, as Juhn et al. (1993) note, this ignores the effect of changes in the prices of unmeasured skills. Based on evidence that dispersion has been increasing in returns to observed skill levels one might expect that returns to unobserved skills also are changing. In particular, if blacks and whites differ in unobserved skills with blacks being positioned lower than whites in that distribution, and the returns to those attributes are increasing, then this may change the wage gap between the groups. Because such changes in the return-to-skill are not black-specific but represent a society wide change in wage inequality, conceptually, one would want to attribute that portion of the change in the residual gap to social inequality rather than discrimination.

Simple evidence that unobserved skills matter in this context can be found by examining within group variation in earnings for specific educational levels of workers. Among groups such as high school graduates or college graduates, some workers are more skilled than others, and based on marginal productivity theory, the more capable workers are, the more they earn. If the distribution of earnings for individuals of a specific educational level are stratified based on unobserved skills and the returns to those skills change over time, then the wage growth of workers at different strata should vary over time.

Figure 7 examines the relative wage trajectories of college-educated workers at various percentiles of our sample over time. Each of the series has been indexed to zero in 1968. Over the 
period of our sample, workers at the $10^{\text {th }}$ percentile have experienced wage reductions while those at the $50^{\text {th }}$ and $90^{\text {th }}$ percentiles have experienced net wage increases. While it is clear from looking at the figure that the distribution of wages for college graduates has widened, it is also clear that wages of the workers at the $10^{\text {th }}$ percentile of the distribution have recovered sharply since the recession of the early 90s. Figure 8 depicts similar information for high school graduates. Wages at the $10^{\text {th }}$ and $50^{\text {th }}$ percentiles have decreased during the period covered by the sample. Since the recession of the early 1990s, the earnings of all groups have been increasing, with the sharpest gains in the last several years experienced by workers at the bottom of the distribution.

Figures 7 and 8 show that within groups, wage variation has increased in net but has narrowed in recent years. To get some sense of changes in inequality throughout the distribution of wages, we subtract the effects of education and experience and calculate the average growth of wages in four subperiods of our sample (1968-1980, 1980-1985, 1986-1992, and 1993-1998). Figure 9 shows the average wage growth throughout the distribution of earnings for the first two subperiods. In the period from 1968-1980, wage growth throughout the distribution was clearly much more equal than during the period from 1980-1985. In both periods, wages below the $50^{\text {th }}$ percentile fell in real terms, but the pattern was much more pronounced from 1980-1985.

Figure 10 makes a similar comparison of wage growth in the periods from 1986-1993 and 1993-1998. Each of these latter periods appears different in that workers in approximately the bottom 15 to 20 percent of the distribution experience relative wage growth and, at least through the bottom third of the distribution in the period from 1993-1996, do not appear to experience meaningful wage erosion. In both periods, wages in the middle of the distribution appear to decline while those in the 
upper percentiles experience the greatest wage growth.

The relationship between these trends in wage dispersion and the black-white wage gap depends on the position of blacks relative to whites in those distributions. If blacks occupy predominantly lower-paying positions within an educational category, such as high school graduates or college graduates, then the evidence shown in Figures 7 and 8 would indicate that their pay should be increasing at a relatively faster rate than the workers in the middle of the income distribution, and this may help reduce the wage gap. However, those gains might be experienced by all low-wage workers within an educational category so that such effects should not be attributed to a reduction in discrimination.

Similarly, if after adjusting for education and experience blacks tend to be in the lower percentiles of the wage distribution, the information in Figure 10 indicates that they might be expected to gain relative to whites in the middle of the distribution but not close the wage gap with workers at the top of the distribution. Nonetheless, depending on the relative distributions of blacks and whites, the wage gains experienced by all workers at the lower end of the distribution may help close the racial wage gap.

Table 6 contains descriptive information on the evolution of the black distribution of wages relative to the wage distribution of whites. For various percentiles in the black distribution of wages, the corresponding percentage of whites earning less than that amount is calculated for specific years of the sample; the percentages reported in the right margin of the table are an average of all years, not just the years listed.

Over time, the distribution of black wages has become more like that of whites, although 
considerable progress has yet to be made before they are equal. For example, in the first year of our sample, 1968, only 7 percent of whites earned less than the bottom quarter of black workers. By 1998, 16 percent of whites earned less than the bottom quarter of black workers. Similarly, in 1968, 63 percent of whites earned less than dollar value of the $90^{\text {th }}$ percentile of the black wage distribution. In 1998,81 percent of whites earned less than the $90^{\text {th }}$ percentile of black wages.

The descriptive evidence suggests that blacks should be gaining relative to whites as they move up through the white distribution of wages. However, as blacks move into more middle income positions, the trend towards wage inequality which has affected all workers would also be expected to affect them.

\section{A. Decomposing the Residual Gap}

Here, we decompose the residual gap in earnings from Table 5 into two components intended to capture changing earnings inequality experienced by all workers as opposed to shifts in the distribution of black workers relative to whites. We follow the decomposition technique developed in Juhn, et al. (1991) and later used by Rodgers (1997). While we provide a brief derivation following their work, more detail can be found in those sources.

Rewrite equation (1) expressing the error term, $\mu_{i t}$, as the multiple of its standard deviation, $\mathrm{F}_{\mathrm{it}}$, and the standardized residual, $2_{i t}=\mu_{i}, \mathrm{~F}_{i t}$, and

$$
Y_{i t}{ }^{\prime} X_{i t} \$ \mathrm{~F}_{i t} 2_{i t}
$$

Then equation (4) can be rewritten as: 


$$
\left.\left.\left.D_{t} \& \bar{D}^{\prime}\left(\left(X_{t}, \&\right) \bar{X}\right) \Phi \%\right) X_{t^{\prime}}\left(\$_{t}\right) \& \overline{\$} \%\right) 2_{t}\left(\mathrm{~F}_{i t}, \& \mathrm{~F}\right) \%\left(() 2_{t}\right) \& \overline{2}\right) \mathrm{F}
$$

where ) $2_{t}=2_{b t}-2_{w t}$. There are four terms in the decomposition. The first term represents the effect of a changing quantity of observable factors holding returns constant at the average for the sample. The second term represents the effect of changing returns holding observables constant. These first two terms were calculated earlier and were shown in Table 5. The third and fourth terms decompose the residual gap into two additional components. The third term captures the effect of a changing deviation of earnings holding the relative distribution constant. Juhn, et al. (1991) refer to this as the unobservable price effect and is meant to capture the impact of changing overall societal inequality on the movement in the black-white wage gap. The last term captures the effect of changes in the relative distributions of blacks and whites holding the standard deviation of earnings constant. This term represents changes in the wage gap over time due to equalization of the percentile rankings of blacks and whites in the wage distribution.

Table 7 extends the information contained in Table 5 by providing this additional decomposition of the change in the residual wage gap. Focusing on what Juhn et al. (1991) refer to as an unobserved price effect, a trend towards widening inequality appears to be inhibiting closure of the black-white wage gap for the period from 1990-98. For the group of male workers with less experience, the major factor explaining the reduction in the wage gap in the last decade is due to the changing positions of blacks relative to whites in the earnings distribution. The estimation procedures we use do not directly explain why blacks are rising in the earnings distribution relative to whites, but a common interpretation is that the portion of the residual gap not explained by price effects is attributable to a lessening of racial 
discrimination. The annual rate of decline in the black-white wage gap which might be attributed to declining discrimination, as shown in Table 7, is (an insignificant) .44 percent for all workers and (a significant) 1.27 percent for workers with less experience.

\section{Conclusions}

After narrowing sharply following the passage of the Civil Rights Act 1964, the wage gap between black and white males remained essentially constant — at about 30 percent—fore nearly 20 years. Since 1992, however, the black-white wage gap has narrowed substantially, and as of 1998, was at its lowest level in history.

A major reason for this change in trend is a reduction in the concentration of employment of blacks in industries and occupations with lower pay. Overall, our results indicate that the wages of black and white male workers converged at a rate of 0.59 percentage point per year between 1990 and 1998. The rate of convergence for younger workers was more rapid at 1.40 percentage points per year. As with the whole sample of male workers, a more favorable distribution of employment by industry and occupation was an in explaining this convergence.

For both the group of all male workers and for younger workers, we find that an general increase in wage inequality has been working against the trend towards black-white wage convergence. Also, among younger workers, much of the convergence in the black-white wage gap is due to unexplained sources. Common interpretations of this residual are that it is due to factors such as a lessening of discrimination or unmeasured differences in productivity, perhaps due to the more widespread adoption of technology in the workplace.

After more than a decade of stasis, the trend observed for the 1990s warrants further 
investigation. Coming to a better understanding of the factors which may be influencing residual inequality, particularly among younger workers, provides an interesting subject for future research. 


\section{References}

Card, David and Krueger, Alan B. 1992a. "Does School Quality Matter? Returns to Education and the Characteristics of Public Schools in the United States." Journal of Political Economy, Vol. 100 (1): 1-40.

Card, David and Krueger, Alan B. 1992b. "School Quality and Black-White Relative Earnings: A Direct Assessment." Quarterly Journal of Economics: 151-200.

Grogger, Jeff. 1996. "Does School Quality Explain the Recent Black/White Wage Trend?" Journal of Labor Economics, Vol. 14 (2): 231-253.

Juhn. Chinhui, Murphy, Kevin M., and Brooks Pierce. 1991. "Accounting for the Slowdown in Black-White Wage Convergence.” In Workers and Their Wages: Changing Patterns in the United States. Ed. Marvin H. Kosters, AEI Press, Washington, DC: 107-143.

Maxwell, Nan L. 1994. "The Effect on Black-White Wage Differences of Differences in the Quantity and Quality of Education.” Industrial and Labor Relations Review, Vol. 47 (2): 1994.

Rodgers, William M. 1997. "Male Sub-Metropolitan Black-White Wage Gaps: New Evidence for the 1980s." Urban Studies, Vol. 34 (8): 1201-1213. 
Table 1: Black-White Wage Gap by Potential Experience for Male Workers

\begin{tabular}{|c|c|c|c|c|c|c|c|}
\hline & \multicolumn{7}{|c|}{ Survey Years } \\
\hline & 1968-1972 & $1973-1977$ & 1978-1982 & 1983-1987 & 1988-1992 & 1993-1997 & 1998 \\
\hline All levels & 0.44 & 0.35 & 0.32 & 0.33 & 0.32 & 0.31 & 0.27 \\
\hline$<6$ & 0.36 & 0.25 & 0.23 & 0.29 & 0.25 & 0.19 & 0.14 \\
\hline $6-10$ & 0.40 & 0.32 & 0.25 & 0.28 & 0.30 & 0.29 & 0.21 \\
\hline $11-15$ & 0.43 & 0.34 & 0.34 & 0.33 & 0.32 & 0.28 & 0.28 \\
\hline $16-20$ & 0.48 & 0.38 & 0.33 & 0.31 & 0.31 & 0.38 & 0.32 \\
\hline $21-25$ & 0.48 & 0.43 & 0.36 & 0.33 & 0.31 & 0.36 & 0.24 \\
\hline $26-30$ & 0.46 & 0.39 & 0.41 & 0.40 & 0.32 & 0.32 & 0.30 \\
\hline $31-35$ & 0.45 & 0.42 & 0.48 & 0.45 & 0.37 & 0.34 & 0.29 \\
\hline$>35$ & 0.45 & 0.38 & 0.36 & 0.40 & 0.34 & 0.28 & 0.30 \\
\hline
\end{tabular}

Source: Calculations by authors from 1968-1998 March Demographic Supplement Files of Current Population Survey 
Table 2: Educational Attainment for Blacks and Whites 1968-1998

Panel A: Black Males

\begin{tabular}{lrrrrrr|r}
\cline { 2 - 8 } & \multicolumn{1}{c}{ Survey Year } \\
\hline & 1968 & 1975 & 1985 & 1990 & 1995 & 1998 & $1968-1998$ \\
\hline Less than high school & 63.2 & 47.2 & 29.1 & 20.3 & 13.1 & 14.7 & 28.3 \\
High school graduates & 25.6 & 34.1 & 39.5 & 45.1 & 42.0 & 40.3 & 38.7 \\
Some college & 7.4 & 11.7 & 18.2 & 20.8 & 28.0 & 29.1 & 20.5 \\
College graduates & 3.8 & 7.0 & 13.2 & 13.8 & 16.9 & 15.9 & 12.5 \\
\hline
\end{tabular}

Panel B: White Males

\begin{tabular}{lcccccc|c}
\cline { 2 - 8 } & 1968 & 1975 & 1985 & 1990 & 1995 & 1998 & $1968-1998$ \\
\hline Less than high school & 36.9 & 25.3 & 16.0 & 13.8 & 11.0 & 11.8 & 18.0 \\
High school graduates & 36.3 & 39.6 & 39.7 & 39.1 & 33.3 & 33.0 & 36.7 \\
Some college & 12.0 & 16.0 & 18.5 & 19.8 & 26.5 & 26.3 & 20.4 \\
College graduates & 14.8 & 19.2 & 25.9 & 27.4 & 29.2 & 28.9 & 24.9
\end{tabular}

Panel C: Black Males Less Than 10 Years Experience

\begin{tabular}{lrrrrrr|c} 
& \multicolumn{7}{c}{ Survey Year } \\
\cline { 2 - 8 } & 1968 & 1975 & 1985 & 1990 & 1995 & 1998 & $1968-1998$ \\
\hline Less than high school & 40.2 & 26.8 & 16.3 & 11.2 & 7.3 & 12.3 & 17.4 \\
High school graduates & 42.8 & 46.0 & 46.1 & 50.4 & 42.1 & 38.1 & 44.4 \\
Some college & 11.1 & 16.5 & 21.5 & 22.8 & 29.9 & 31.2 & 23.0 \\
College graduates & 6.0 & 10.7 & 16.1 & 15.7 & 20.7 & 18.5 & 15.3
\end{tabular}

Panel D: White Males Less Than 10 Years Experience

\begin{tabular}{lccccrr|c} 
& \multicolumn{7}{c}{ Survey Year } \\
\hline & 1968 & 1975 & 1985 & 1990 & 1995 & 1998 & $1968-1998$ \\
\hline Less than high school & 20.0 & 12.0 & 11.5 & 11.7 & 9.5 & 10.6 & 12.2 \\
High school graduates & 43.0 & 40.9 & 40.6 & 39.1 & 32.8 & 31.3 & 37.8 \\
Some college & 16.2 & 21.8 & 20.2 & 19.4 & 26.2 & 27.8 & 22.1 \\
College graduates & 20.8 & 25.3 & 27.8 & 29.8 & 31.4 & 30.4 & 27.9
\end{tabular}

Source: Calculations by authors from 1968-1998 March Demographic Supplement Files of Current Population Survey 
Table 3: Proportional Employment by Race and Industry in Selected Years

Panel A: All Black Male Workers

\begin{tabular}{lcccccc|c} 
& \multicolumn{7}{c}{ Survey Year } \\
\cline { 2 - 8 } & 1968 & 1975 & 1985 & 1990 & 1995 & 1998 & $1968-1998$ \\
\hline Agriculture & 5.3 & 2.8 & 2.4 & 1.4 & 1.5 & 0.7 & 2.1 \\
Business services & 1.5 & 1.5 & 3.6 & 3.7 & 4.7 & 5.9 & 3.8 \\
Communication & 0.4 & 0.7 & 1.6 & 1.4 & 1.5 & 2.3 & 1.4 \\
Construction & 10.9 & 11.1 & 7.5 & 7.8 & 7.6 & 9.0 & 8.8 \\
Education & 4.3 & 5.6 & 5.3 & 4.8 & 4.4 & 4.2 & 4.7 \\
& & & & & & & \\
Entertainment & 1.1 & 0.6 & 1.2 & 1.1 & 1.6 & 1.1 & 1.1 \\
Finance & 0.4 & 1.1 & 1.6 & 1.4 & 1.7 & 1.3 & 1.3 \\
Forestry and kindred products & 0.2 & 0.0 & 0.1 & 0.1 & 0.0 & 0.0 & 0.1 \\
Health service & 0.4 & 1.2 & 0.9 & 1.1 & 2.0 & 1.4 & 1.2 \\
Hospitals & 3.9 & 3.6 & 4.6 & 3.6 & 3.2 & 3.2 & 3.6 \\
& & & & & & & \\
Household services & 0.5 & 0.5 & 0.1 & 0.1 & 0.2 & 0.1 & 0.2 \\
Insurance & 1.6 & 1.9 & 2.0 & 3.0 & 2.6 & 2.3 & 2.3 \\
Manufacturing & 33.5 & 34.5 & 29.1 & 25.2 & 23.0 & 22.9 & 27.2 \\
Mining & 0.4 & 0.4 & 0.6 & 0.6 & 0.2 & 0.5 & 0.5 \\
Other professional & 0.4 & 0.9 & 1.5 & 2.1 & 2.2 & 2.5 & 1.7 \\
& & & & & & & \\
Personal services & 2.2 & 1.3 & 1.9 & 2.5 & 1.5 & 2.1 & 1.9 \\
Public service & 5.6 & 5.5 & 6.9 & 10.4 & 10.8 & 8.2 & 8.2 \\
Repair services & 1.4 & 0.9 & 2.0 & 2.0 & 2.0 & 1.6 & 1.7 \\
Retail trade & 10.0 & 9.2 & 11.5 & 10.9 & 11.7 & 12.2 & 11.1 \\
Transportation & 8.4 & 8.1 & 7.9 & 8.3 & 9.4 & 11.1 & 9.0 \\
& & & & & & & \\
Utilities & 2.8 & 2.8 & 3.4 & 3.4 & 2.4 & 1.7 & 2.7 \\
Welfare services & 0.7 & 1.1 & 0.9 & 1.3 & 1.5 & 1.5 & 1.2 \\
Wholesale trade & 4.3 & 4.7 & 3.5 & 4.2 & 4.3 & 4.3 & 4.2 \\
\hline
\end{tabular}


Panel B: All Male White Workers

\begin{tabular}{lcccccc|c} 
& \multicolumn{7}{c}{ Survey Year } \\
\cline { 2 - 7 } & 1968 & 1975 & 1985 & 1990 & 1995 & 1998 & $1968-1998$ \\
\hline Agriculture & 2.8 & 2.3 & 2.2 & 2.4 & 2.6 & 2.5 & 2.5 \\
Business services & 1.4 & 1.7 & 2.8 & 3.8 & 4.2 & 4.9 & 3.3 \\
Communication & 1.4 & 1.6 & 1.8 & 1.5 & 1.7 & 1.8 & 1.6 \\
Construction & 9.1 & 10.5 & 10.5 & 10.8 & 10.2 & 10.9 & 10.4 \\
Education & 4.5 & 5.3 & 4.9 & 4.3 & 4.6 & 4.4 & 4.7 \\
& & & & & & & \\
Entertainment & 0.8 & 0.7 & 0.9 & 0.9 & 1.2 & 1.5 & 1.0 \\
Finance & 1.6 & 1.7 & 2.1 & 2.3 & 2.1 & 2.1 & 2.0 \\
Forestry and kindred products & 0.2 & 0.2 & 0.3 & 0.2 & 0.2 & 0.2 & 0.2 \\
Health service & 0.5 & 0.9 & 1.0 & 1.2 & 1.4 & 1.6 & 1.2 \\
Hospitals & 1.2 & 1.4 & 1.6 & 1.5 & 1.9 & 1.8 & 1.6 \\
& & & & & & & \\
Household services & 0.1 & 0.1 & 0.1 & 0.1 & 0.1 & 0.1 & 0.1 \\
Insurance & 2.6 & 2.8 & 2.7 & 3.0 & 2.8 & 2.9 & 2.8 \\
Manufacturing & 37.5 & 33.1 & 28.8 & 26.3 & 24.4 & 23.7 & 28.4 \\
Mining & 1.4 & 1.5 & 1.9 & 1.2 & 1.1 & 1.0 & 1.3 \\
Other Professional & 1.3 & 2.0 & 3.1 & 3.5 & 4.5 & 4.2 & 3.2 \\
& & & & & & & \\
Personal services & 1.3 & 1.0 & 1.1 & 1.4 & 1.3 & 1.3 & 1.3 \\
Public service & 5.7 & 5.7 & 5.9 & 7.4 & 7.3 & 6.2 & 6.4 \\
Repair services & 1.3 & 1.5 & 2.3 & 2.3 & 2.1 & 2.2 & 2.0 \\
Retail trade & 10.2 & 11.1 & 11.4 & 11.9 & 12.2 & 12.4 & 11.6 \\
Transportation & 7.5 & 6.8 & 5.9 & 5.9 & 5.7 & 5.9 & 6.2 \\
& & & & & & & \\
Utilities & 2.5 & 2.1 & 2.4 & 2.3 & 2.2 & 2.1 & 2.3 \\
Welfare services & 0.8 & 1.0 & 0.5 & 0.4 & 0.5 & 0.7 & 0.6 \\
Wholesale trade & 4.5 & 5.2 & 6.0 & 5.6 & 6.0 & 5.5 & 5.5 \\
\hline & & & & & & & \\
& & & & & &
\end{tabular}


Panel C: Black Male Workers Less Than 10 Years Experience

\begin{tabular}{lcccccc|c} 
& \multicolumn{7}{c}{ Survey Year } \\
\cline { 2 - 8 } & 1968 & 1975 & 1985 & 1990 & 1995 & 1998 & $1968-1998$ \\
\hline Agriculture & 4.4 & 1.9 & 2.3 & 1.4 & 0.9 & 0.6 & 1.8 \\
Business services & 3.1 & 1.3 & 4.8 & 5.9 & 6.4 & 9.0 & 5.3 \\
Communication & 0.4 & 1.1 & 1.3 & 0.8 & 1.2 & 3.3 & 1.4 \\
Construction & 8.6 & 10.7 & 8.6 & 6.1 & 5.3 & 8.0 & 7.8 \\
Education & 4.8 & 5.8 & 3.8 & 2.5 & 3.7 & 3.4 & 3.9 \\
& & & & & & & \\
Entertainment & 0.8 & 0.5 & 1.7 & 1.7 & 1.9 & 1.9 & 1.5 \\
Finance & 0.3 & 1.9 & 2.8 & 2.0 & 3.5 & 1.9 & 2.2 \\
Forestry and kindred products & 0.0 & 0.0 & 0.0 & 0.0 & 0.1 & 0.0 & 0.0 \\
Health service & 0.3 & 1.2 & 1.1 & 1.1 & 2.2 & 2.0 & 1.4 \\
Hospitals & 4.7 & 4.0 & 3.3 & 4.0 & 2.5 & 2.7 & 3.4 \\
& & & & & & & \\
Household services & 0.4 & 0.6 & 0.2 & 0.1 & 0.0 & 0.0 & 0.2 \\
Insurance & 1.7 & 2.1 & 1.9 & 2.6 & 1.6 & 1.3 & 1.9 \\
Manufacturing & 35.9 & 34.4 & 25.3 & 21.9 & 22.0 & 19.0 & 25.5 \\
Mining & 0.0 & 0.2 & 0.5 & 0.3 & 0.0 & 0.3 & 0.2 \\
Other professional & 0.1 & 0.6 & 1.6 & 3.2 & 1.9 & 2.1 & 1.7 \\
& & & & & & & \\
Personal services & 2.0 & 0.7 & 2.5 & 4.1 & 2.2 & 2.2 & 2.3 \\
Public service & 5.6 & 4.4 & 5.5 & 10.5 & 10.8 & 7.0 & 7.5 \\
Repair services & 1.7 & 1.0 & 2.3 & 2.8 & 1.8 & 1.3 & 1.9 \\
Retail trade & 10.7 & 12.9 & 16.5 & 14.5 & 19.0 & 16.9 & 15.4 \\
Transportation & 6.9 & 5.4 & 6.6 & 6.6 & 6.2 & 7.8 & 6.6 \\
& & & & & & & \\
Utilities & 2.2 & 3.0 & 2.4 & 2.2 & 1.2 & 1.3 & 2.0 \\
Welfare services & 0.4 & 1.7 & 1.4 & 1.4 & 1.5 & 2.2 & 1.5 \\
Wholesale trade & 4.9 & 4.5 & 3.7 & 4.5 & 4.3 & 5.9 & 4.6 \\
\hline
\end{tabular}


Panel D: Male White Workers Less Than 10 Years Experience

\begin{tabular}{lcccccc|c} 
& \multicolumn{7}{c}{ Survey Year } \\
\cline { 2 - 8 } & 1968 & 1975 & 1985 & 1990 & 1995 & 1998 & $1968-1998$ \\
\hline Agriculture & 2.9 & 2.6 & 3.1 & 3.0 & 3.1 & 3.1 & 3.0 \\
Business services & 1.5 & 2.0 & 3.3 & 4.7 & 5.6 & 5.9 & 3.9 \\
Communication & 2.0 & 1.8 & 1.4 & 1.0 & 1.5 & 1.9 & 1.6 \\
Construction & 8.7 & 10.9 & 11.3 & 11.8 & 10.6 & 11.0 & 10.8 \\
Education & 5.5 & 6.3 & 3.5 & 3.1 & 3.4 & 3.3 & 4.1 \\
& & & & & & & \\
Entertainment & 0.8 & 0.8 & 1.1 & 0.9 & 1.7 & 1.9 & 1.2 \\
Finance & 2.4 & 2.0 & 2.4 & 2.7 & 2.7 & 2.9 & 2.5 \\
Forestry and kindred products & 0.2 & 0.2 & 0.3 & 0.2 & 0.0 & 0.1 & 0.2 \\
Health service & 0.6 & 1.0 & 1.0 & 0.9 & 1.2 & 1.3 & 1.0 \\
Hospitals & 1.2 & 1.6 & 2.0 & 1.8 & 2.0 & 1.9 & 1.8 \\
& & & & & & & \\
Household services & 0.0 & 0.0 & 0.1 & 0.1 & 0.1 & 0.0 & 0.1 \\
Insurance & 2.5 & 2.5 & 2.1 & 2.8 & 2.4 & 2.5 & 2.5 \\
Manufacturing & 37.4 & 30.4 & 26.8 & 23.1 & 21.3 & 21.6 & 26.2 \\
Mining & 0.8 & 1.5 & 1.9 & 0.9 & 0.6 & 0.8 & 1.1 \\
Other professional & 2.0 & 2.4 & 3.6 & 4.0 & 4.6 & 4.4 & 3.6 \\
& & & & & & & \\
Personal services & 1.5 & 0.9 & 1.3 & 1.7 & 1.4 & 1.4 & 1.4 \\
Public service & 4.8 & 5.1 & 4.7 & 7.5 & 6.8 & 5.9 & 5.8 \\
Repair services & 1.7 & 1.9 & 2.9 & 2.9 & 2.4 & 2.3 & 2.4 \\
Retail trade & 11.5 & 13.7 & 14.4 & 15.3 & 16.7 & 17.0 & 14.9 \\
Transportation & 5.2 & 4.8 & 4.5 & 4.3 & 4.1 & 3.9 & 4.4 \\
& & & & & & & \\
Utilities & 2.2 & 1.7 & 1.9 & 1.3 & 1.1 & 0.9 & 1.5 \\
Welfare services & 0.7 & 0.9 & 0.5 & 0.4 & 0.6 & 0.7 & 0.6 \\
Wholesale trade & 4.0 & 5.1 & 6.0 & 5.7 & 6.1 & 5.4 & 5.5 \\
\hline & & & & & & &
\end{tabular}

Source: Calculations by authors from 1968-1998 March Demographic Supplement Files of Current Population Survey 
Table 4: Employment by Race and Occupation in Selected Years

Panel A: All Black Male Workers

\begin{tabular}{lcccccc|c} 
& \multicolumn{7}{c}{ Survey Year } \\
\hline & 1968 & 1975 & 1985 & 1990 & 1995 & 1998 & $1968-1998$ \\
\hline Clerical & 7.9 & 7.7 & 8.4 & 8.5 & 9.2 & 8.8 & 8.5 \\
Craftsmen & 14.1 & 17.7 & 26.0 & 25.8 & 24.6 & 25.2 & 22.9 \\
Farm labor & 4.3 & 1.9 & 3.1 & 2.4 & 1.8 & 1.0 & 2.3 \\
Farm manager & 0.4 & 0.6 & 0.1 & 0.1 & 0.0 & 0.0 & 0.2 \\
Forestry & 0.2 & 0.0 & 0.1 & 0.1 & 0.0 & 0.0 & 0.1 \\
Managers & 2.4 & 3.8 & 9.7 & 9.0 & 11.0 & 11.3 & 8.4 \\
Nonfarm labor & 19.3 & 15.8 & 5.0 & 4.0 & 5.0 & 4.9 & 8.1 \\
Operatives & 30.1 & 29.3 & 18.3 & 18.1 & 16.5 & 17.0 & 20.6 \\
Other services & 14.2 & 15.1 & 18.4 & 16.5 & 15.1 & 14.6 & 15.7 \\
Professional & 5.9 & 6.5 & 7.8 & 8.6 & 10.4 & 11.2 & 8.7 \\
Sales & 1.4 & 1.6 & 2.9 & 4.0 & 4.0 & 4.2 & 3.2 \\
\hline
\end{tabular}

Panel B: All White Male Workers

\begin{tabular}{lcccccc|c} 
& \multicolumn{7}{c}{ Survey Year } \\
\cline { 2 - 7 } & 1968 & 1975 & 1985 & 1990 & 1995 & 1998 & $1968-1998$ \\
\hline Clerical & 7.8 & 6.6 & 5.9 & 5.7 & 5.2 & 5.2 & 6.0 \\
Craftsmen & 23.9 & 23.9 & 28.9 & 26.9 & 25.9 & 26.6 & 26.2 \\
Farm labor & 1.3 & 1.3 & 2.0 & 2.0 & 2.1 & 2.3 & 1.9 \\
Farm manager & 1.1 & 0.6 & 0.4 & 0.6 & 0.6 & 0.5 & 0.6 \\
Forestry & 0.2 & 0.2 & 0.3 & 0.2 & 0.2 & 0.2 & 0.2 \\
Managers & 13.3 & 14.6 & 20.3 & 20.8 & 21.3 & 21.4 & 19.0 \\
Nonfarm labor & 4.8 & 5.9 & 2.4 & 2.6 & 2.7 & 2.5 & 3.4 \\
Operatives & 22.0 & 19.2 & 9.7 & 9.0 & 9.0 & 8.8 & 12.3 \\
Other services & 5.2 & 6.5 & 6.9 & 7.2 & 7.5 & 7.8 & 6.9 \\
Professional & 14.7 & 15.6 & 16.4 & 16.7 & 17.3 & 17.3 & 16.4 \\
Sales & 5.6 & 5.7 & 6.6 & 6.7 & 6.8 & 6.3 & 6.3 \\
\hline
\end{tabular}


Panel C: Black Male Workers Less Than 10 Years Experience

\begin{tabular}{lcccccc|c} 
& \multicolumn{7}{c}{ Survey Year } \\
\hline & 1968 & 1975 & 1985 & 1990 & 1995 & 1998 & $1968-1998$ \\
\hline Professional & 8.1 & 8.6 & 9.3 & 9.6 & 10.3 & 14.0 & 10.1 \\
Managers & 3.4 & 3.8 & 7.8 & 6.7 & 8.9 & 10.4 & 7.1 \\
Clerical & 11.5 & 9.8 & 10.2 & 9.9 & 12.5 & 9.3 & 10.5 \\
Sales & 2.3 & 2.9 & 3.6 & 6.7 & 6.2 & 5.3 & 4.7 \\
Craftsmen & 11.8 & 15.6 & 25.7 & 22.3 & 19.4 & 21.5 & 20.0 \\
Operatives & 28.8 & 29.0 & 16.2 & 16.7 & 13.8 & 15.1 & 19.1 \\
Nonfarm labor & 17.8 & 15.3 & 4.4 & 4.0 & 5.7 & 6.4 & 8.1 \\
Other services & 12.1 & 13.3 & 18.8 & 18.2 & 18.8 & 13.1 & 16.1 \\
Farm manager & 0.0 & 0.2 & 0.3 & 0.0 & 0.0 & 0.0 & 0.1 \\
Farm labor & 4.2 & 1.6 & 2.7 & 2.1 & 1.1 & 1.5 & 2.1 \\
Forestry & 0.0 & 0.0 & 0.0 & 0.0 & 0.1 & 0.0 & 0.0 \\
\hline
\end{tabular}

Panel D: White Male Workers Less Than 10 Years Experience

\begin{tabular}{lcccccc|c} 
& \multicolumn{7}{c}{ Survey Year } \\
\hline & 1968 & 1975 & 1985 & 1990 & 1995 & 1998 & $1968-1998$ \\
\hline Professional & 19.9 & 19.1 & 17.9 & 18.3 & 17.5 & 18.8 & 18.5 \\
Managers & 9.5 & 11.1 & 15.0 & 14.6 & 16.5 & 15.9 & 14.0 \\
Clerical & 9.5 & 6.7 & 5.8 & 5.7 & 5.3 & 5.9 & 6.3 \\
Sales & 5.4 & 6.2 & 6.9 & 7.3 & 7.6 & 7.3 & 6.9 \\
Craftsmen & 20.0 & 21.6 & 29.4 & 27.7 & 25.3 & 25.4 & 25.3 \\
Operatives & 23.7 & 19.8 & 10.7 & 8.6 & 9.1 & 8.7 & 12.8 \\
Nonfarm labor & 5.1 & 7.6 & 2.9 & 3.4 & 3.6 & 3.2 & 4.2 \\
Other services & 4.2 & 5.8 & 7.3 & 7.9 & 9.2 & 9.2 & 7.4 \\
Farm manager & 0.6 & 0.4 & 0.4 & 0.4 & 0.3 & 0.2 & 0.4 \\
Farm labor & 1.8 & 1.5 & 2.8 & 2.8 & 3.1 & 2.9 & 2.5 \\
Forestry & 0.2 & 0.2 & 0.3 & 0.2 & 0.0 & 0.1 & 0.2 \\
\hline
\end{tabular}

Source: Calculations by authors from 1968-1998 March Demographic Supplement Files of Current Population Survey 
Table 5: Black-White Wage 1968-1998

B.All Male Workers ${ }^{\mathrm{a}}$

\begin{tabular}{lccc}
\hline & $68-79$ & $80-89$ & $90-98$ \\
\hline Total & 1.23 & -0.24 & 0.59 \\
& $(0.15)$ & $(0.38)$ & $(0.29)$ \\
Observables & 0.94 & -0.07 & 0.25 \\
& $(0.07)$ & $(0.16)$ & $(0.12)$ \\
Prices & 0.28 & -0.28 & -0.12 \\
& $(0.03)$ & $(0.06)$ & $(0.05)$ \\
Quantities & 0.66 & 0.21 & 0.37 \\
& $(0.06)$ & $(0.11)$ & $(0.14)$ \\
\hline
\end{tabular}

Education, Experience, and Location

\begin{tabular}{lccc} 
Observables & 0.38 & 0.04 & 0.16 \\
& $(0.04)$ & $(0.08)$ & $(0.10)$ \\
Prices & -0.03 & -0.15 & 0.07 \\
& $(0.03)$ & $(0.06)$ & $(0.08)$ \\
Quantities & 0.41 & 0.18 & 0.10 \\
& $(0.04)$ & $(0.07)$ & $(0.09)$ \\
\hline
\end{tabular}

$\underline{\text { Industry and Occupation of Employment }}$

\begin{tabular}{lccc} 
Observables & 0.56 & -0.11 & 0.09 \\
\multirow{4}{*}{ Prices } & $(0.06)$ & $(0.11)$ & $(0.14)$ \\
& 0.31 & -0.13 & -0.18 \\
Quantities & $(0.04)$ & $(0.08)$ & $(0.10)$ \\
& 0.25 & 0.03 & 0.28 \\
& $(0.04)$ & $(0.07)$ & $(0.09)$ \\
\hline \multirow{4}{*}{ Residual Inequality } & & \\
\cline { 2 - 4 } Total & & & \\
& 0.28 & -0.17 & 0.34 \\
& $(0.13)$ & $(0.25)$ & $(0.33)$ \\
\hline
\end{tabular}




\section{B. Male Workers with Less Than 10 Years Experience ${ }^{\mathrm{a}}$}

\begin{tabular}{lccc}
\hline & $68-79$ & $80-89$ & $90-98$ \\
\hline Total & 1.34 & -0.66 & 1.40 \\
Observables & $(0.26)$ & $(0.49)$ & $(0.65)$ \\
& 1.08 & -0.18 & 0.19 \\
Prices & $(0.11)$ & $(0.20)$ & $(0.27)$ \\
& 0.39 & -0.31 & 0.05 \\
Quantities & $(0.05)$ & $(0.09)$ & $(0.12)$ \\
& 0.68 & 0.13 & 0.14 \\
& $(0.09)$ & $(0.17)$ & $(0.23)$ \\
\hline
\end{tabular}

Education, Experience, and Location

\begin{tabular}{|c|c|c|c|}
\hline Observables & $\begin{array}{c}0.57 \\
(0.10)\end{array}$ & $\begin{array}{c}0.17 \\
(0.18)\end{array}$ & $\begin{array}{c}-0.20 \\
(0.24)\end{array}$ \\
\hline Prices & $\begin{array}{c}0.03 \\
(0.03)\end{array}$ & $\begin{array}{l}-0.16 \\
(0.06)\end{array}$ & $\begin{array}{c}0.04 \\
(0.08)\end{array}$ \\
\hline Quantities & $\begin{array}{c}0.54 \\
(0.08)\end{array}$ & $\begin{array}{c}0.33 \\
(0.15)\end{array}$ & $\begin{array}{c}-0.24 \\
(0.20)\end{array}$ \\
\hline \multicolumn{4}{|c|}{ Industry and Occupation of Employment } \\
\hline Observables & $\begin{array}{c}0.50 \\
(0.08)\end{array}$ & $\begin{array}{l}-0.35 \\
(0.15)\end{array}$ & $\begin{array}{c}0.39 \\
(0.20)\end{array}$ \\
\hline Prices & $\begin{array}{c}0.36 \\
(0.05)\end{array}$ & $\begin{array}{c}-0.15 \\
(0.09)\end{array}$ & $\begin{array}{c}0.01 \\
(0.12)\end{array}$ \\
\hline Quantities & $\begin{array}{c}0.14 \\
(0.06)\end{array}$ & $\begin{array}{l}-0.20 \\
(0.12)\end{array}$ & $\begin{array}{c}0.38 \\
(0.16)\end{array}$ \\
\hline \multicolumn{4}{|c|}{$\underline{\text { Residual Inequality }}$} \\
\hline Total & $\begin{array}{c}0.27 \\
(0.22)\end{array}$ & $\begin{array}{c}-0.47 \\
(0.41)\end{array}$ & $\begin{array}{c}1.21 \\
(0.54)\end{array}$ \\
\hline
\end{tabular}

\footnotetext{
${ }^{a}$ Table entries take the form of estimate (standard error). The regressors included in the estimations are region of residence, a quartic in potential experience, education, industry, and occupation. The industry and occupation variables are grouped together under the appropriate heading in the decompositions. Education, location, and experience are similarly grouped.
}

Source: Calculations by authors from 1968-1998 March Demographic Supplement Files of Current Population Survey. 
Table 6: Percentage of White Males Earning Less Than Blacks by Percentile and Year

\begin{tabular}{l|cccccc|c}
\hline Percentiles & 1968 & 1975 & 1985 & 1990 & 1995 & 1998 & $1968-1998$ \\
\hline $10^{\text {th }}$ & 3.3 & 4.2 & 5.1 & 6.2 & 5.9 & 7.3 & 5.0 \\
$25^{\text {th }}$ & 7.1 & 9.9 & 12.2 & 14.8 & 14.7 & 16.3 & 11.8 \\
$50^{\text {th }}$ & 16.8 & 24.9 & 27.3 & 30.4 & 32.8 & 36.3 & 27.6 \\
$75^{\text {th }}$ & 36.8 & 49.3 & 52.0 & 55.4 & 59.0 & 59.2 & 52.6 \\
$90^{\text {th }}$ & 62.5 & 71.1 & 72.7 & 77.8 & 80.1 & 80.7 & 74.4 \\
\hline
\end{tabular}

Source: Calculations by authors from 1968-1998 March Demographic Supplement to the CPS. 
Table 7: Black-White Wage Convergence Controlling for Residual Inequality Changes 1968-1998

1.All Male Workers ${ }^{\mathrm{a}}$

\begin{tabular}{lccc}
\hline & $68-79$ & $80-89$ & $90-98$ \\
\hline Total & 1.23 & -0.24 & 0.59 \\
& $(0.15)$ & $(0.29)$ & $(0.38)$ \\
Observables & 0.94 & -0.07 & 0.25 \\
& $(0.07)$ & $(0.12)$ & $(0.16)$ \\
Prices & 0.28 & -0.28 & -0.12 \\
& $(0.03)$ & $(0.05)$ & $(0.06)$ \\
Quantities & 0.66 & 0.21 & 0.37 \\
& $(0.06)$ & $(0.11)$ & $(0.14)$ \\
\hline
\end{tabular}

Education, Experience, and Location

\begin{tabular}{lccc} 
Observables & 0.38 & 0.04 & 0.16 \\
& $(0.04)$ & $(0.08)$ & $(0.10)$ \\
Prices & -0.03 & -0.15 & 0.07 \\
& $(0.03)$ & $(0.06)$ & $(0.08)$ \\
Quantities & 0.41 & 0.18 & 0.10 \\
& $(0.04)$ & $(0.07)$ & $(0.09)$ \\
\hline
\end{tabular}

Industry and Occupation of Employment

\begin{tabular}{lccc} 
Observables & 0.56 & -0.11 & 0.09 \\
& $(0.06)$ & $(0.11)$ & $(0.14)$ \\
Prices & 0.31 & -0.13 & -0.18 \\
& $(0.04)$ & $(0.08)$ & $(0.10)$ \\
Quantities & 0.25 & 0.03 & 0.28 \\
& $(0.04)$ & $(0.07)$ & $(0.09)$ \\
\hline
\end{tabular}

$\underline{\text { Residual Inequality }}$

\begin{tabular}{lccc} 
Total & 0.28 & -0.17 & 0.34 \\
& $(0.13)$ & $(0.25)$ & $(0.33)$ \\
Unobservable Price Effect & -0.27 & 0.03 & -0.11 \\
& $(0.05)$ & $(0.10)$ & $(0.13)$ \\
Unexplained Inequality & 0.55 & -0.20 & 0.44 \\
& $(0.12)$ & $(0.23)$ & $(0.30)$ \\
\hline
\end{tabular}




\section{B. Male Workers with Less Than 10 Years Experience ${ }^{\mathrm{a}}$}

\begin{tabular}{lccc}
\hline & $68-79$ & $80-89$ & $90-98$ \\
\hline Total & 1.34 & -0.66 & 1.40 \\
& $(0.26)$ & $(0.49)$ & $(0.65)$ \\
Observables & 1.08 & -0.18 & 0.19 \\
& $(0.11)$ & $(0.27)$ & $(0.20)$ \\
Prices & 0.39 & -0.31 & 0.05 \\
& $(0.05)$ & $(0.09)$ & $(0.12)$ \\
Quantities & 0.68 & 0.13 & 0.14 \\
& $(0.09)$ & $(0.17)$ & $(0.23)$ \\
\hline
\end{tabular}

Education, Experience, and Location

\begin{tabular}{lccc} 
Observables & 0.57 & 0.17 & -0.20 \\
& $(0.10)$ & $(0.18)$ & $(0.24)$ \\
Prices & 0.03 & -0.16 & 0.04 \\
& $(0.03)$ & $(0.06)$ & $(0.08)$ \\
Quantities & 0.54 & 0.33 & -0.24 \\
& $(0.08)$ & $(0.15)$ & $(0.20)$ \\
\hline
\end{tabular}

Industry and Occupation of Employment

$\begin{array}{lccc}\text { Observables } & 0.50 & -0.35 & 0.39 \\ & (0.08) & (0.15) & (0.20) \\ \text { Prices } & 0.36 & -0.15 & 0.01 \\ & (0.05) & (0.09) & (0.12) \\ \text { Quantities } & 0.14 & -0.20 & 0.38 \\ & (0.06) & (0.12) & (0.16)\end{array}$

\begin{tabular}{lccc}
\hline \multicolumn{4}{c}{ Residual Inequality } \\
& & \\
\cline { 2 - 3 } Total & 0.27 & -0.47 & 1.21 \\
& $(0.22)$ & $(0.41)$ & $(0.54)$ \\
Unobservable Price Effect & -0.05 & 0.07 & -0.07 \\
& $(0.07)$ & $(0.12)$ & $(0.17)$ \\
Residual Inequality & 0.32 & -0.54 & 1.27 \\
& $(0.22)$ & $(0.42)$ & $(0.56)$ \\
\hline
\end{tabular}

\footnotetext{
${ }^{a}$ Table entries take the form of estimate (standard error). The regressors included in the estimations are region of residence, a quartic in potential experience, education, industry, and occupation. The industry and occupation variables are grouped together under the appropriate heading in the decompositions. Education, location, and experience are similarly grouped.
} 
Figure 1: Black-White Wage Gap 1968-1998

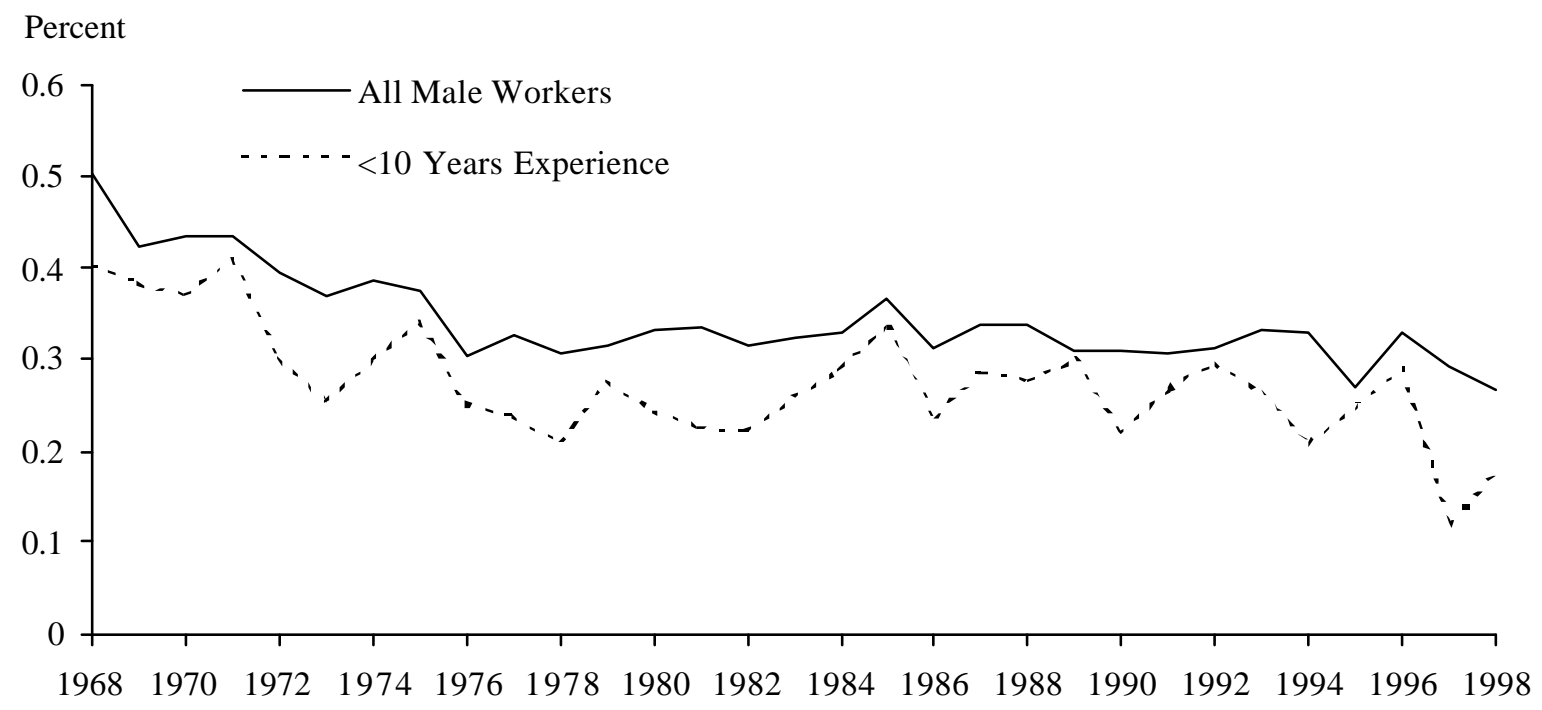

Figure 2: Trends in College Wage Premiums

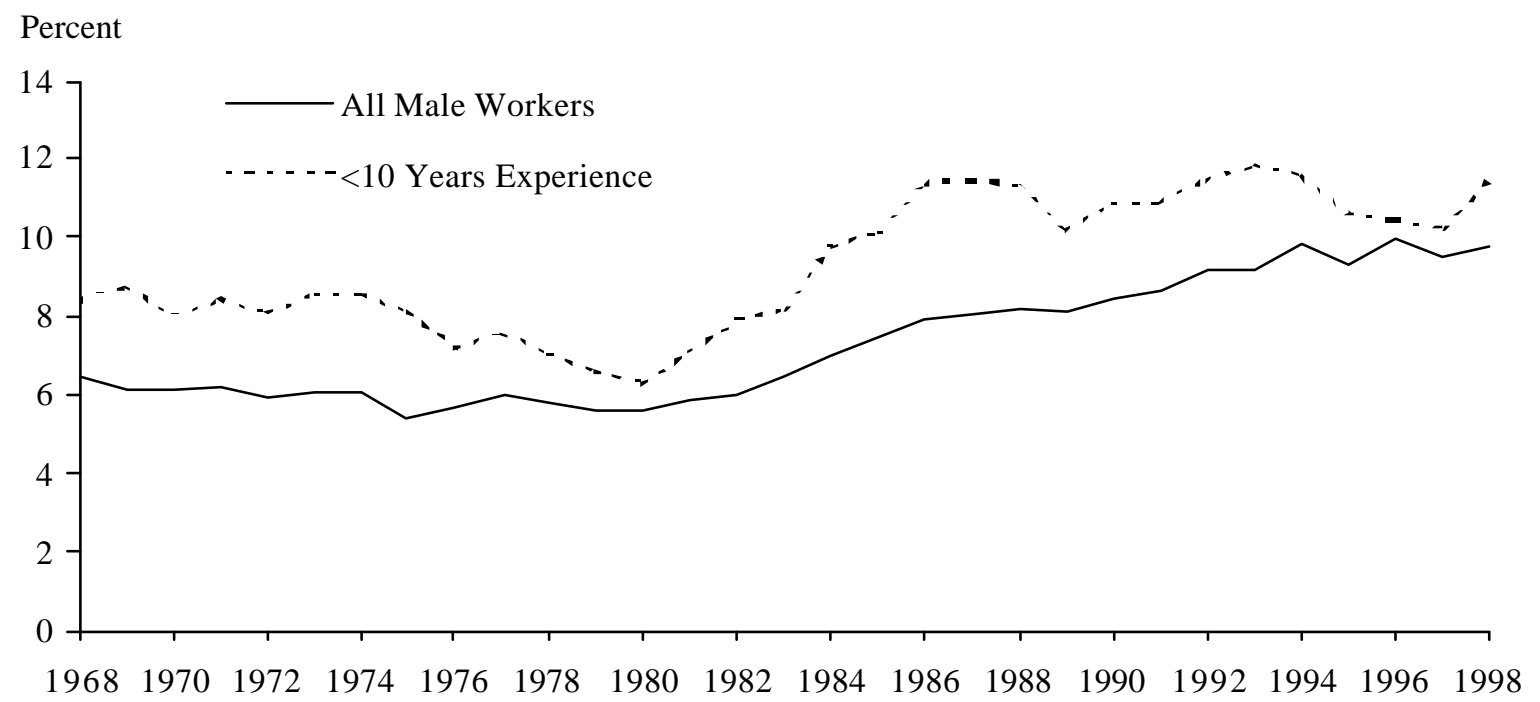

Source: Calculations by authors from 1968-1998 March Demographic Supplement to the CPS. 
Figure 3: Average Weekly Earnings of Selected Industries 1968-1998

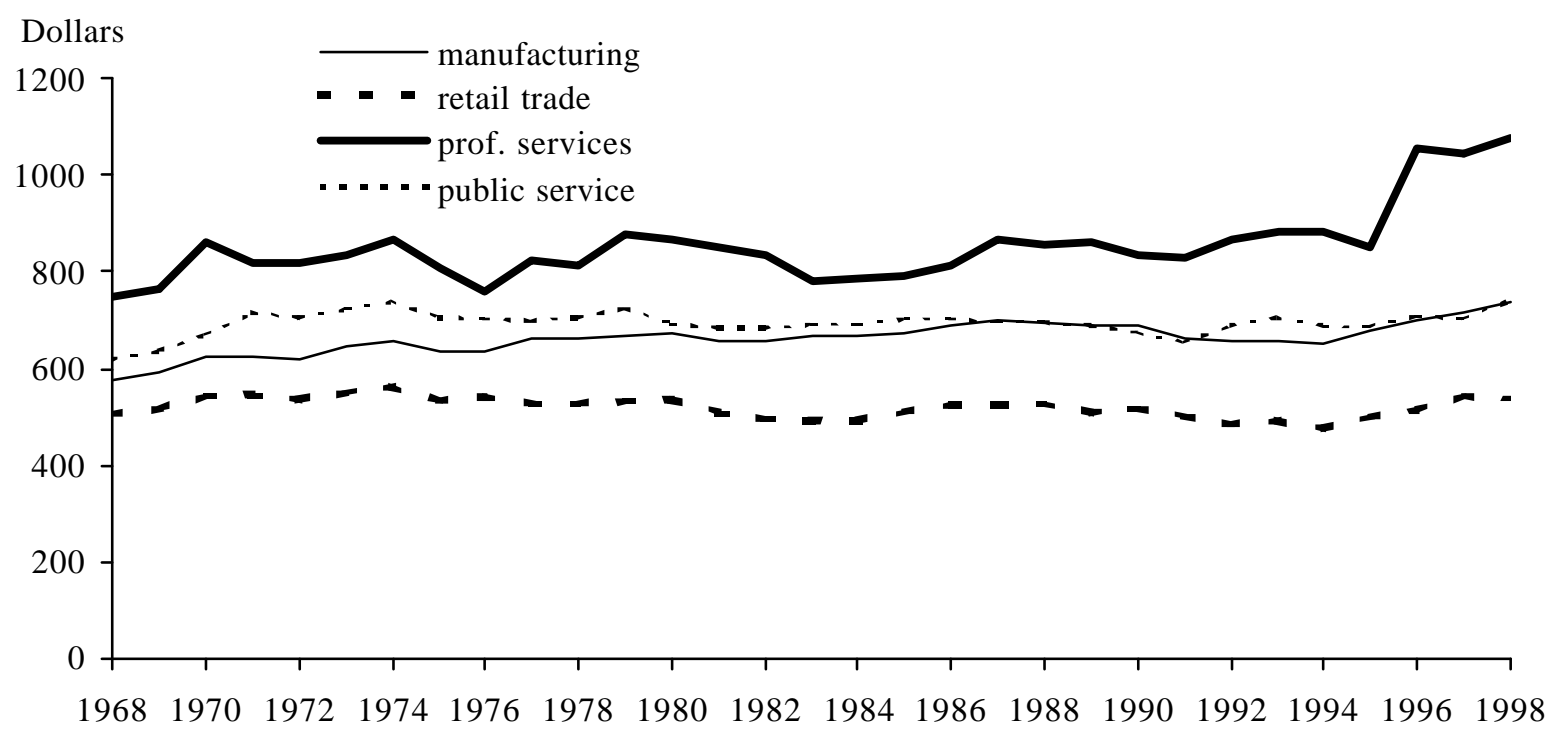

Figure 4: Weekly Earnings of Selected Occupations 1968-1998

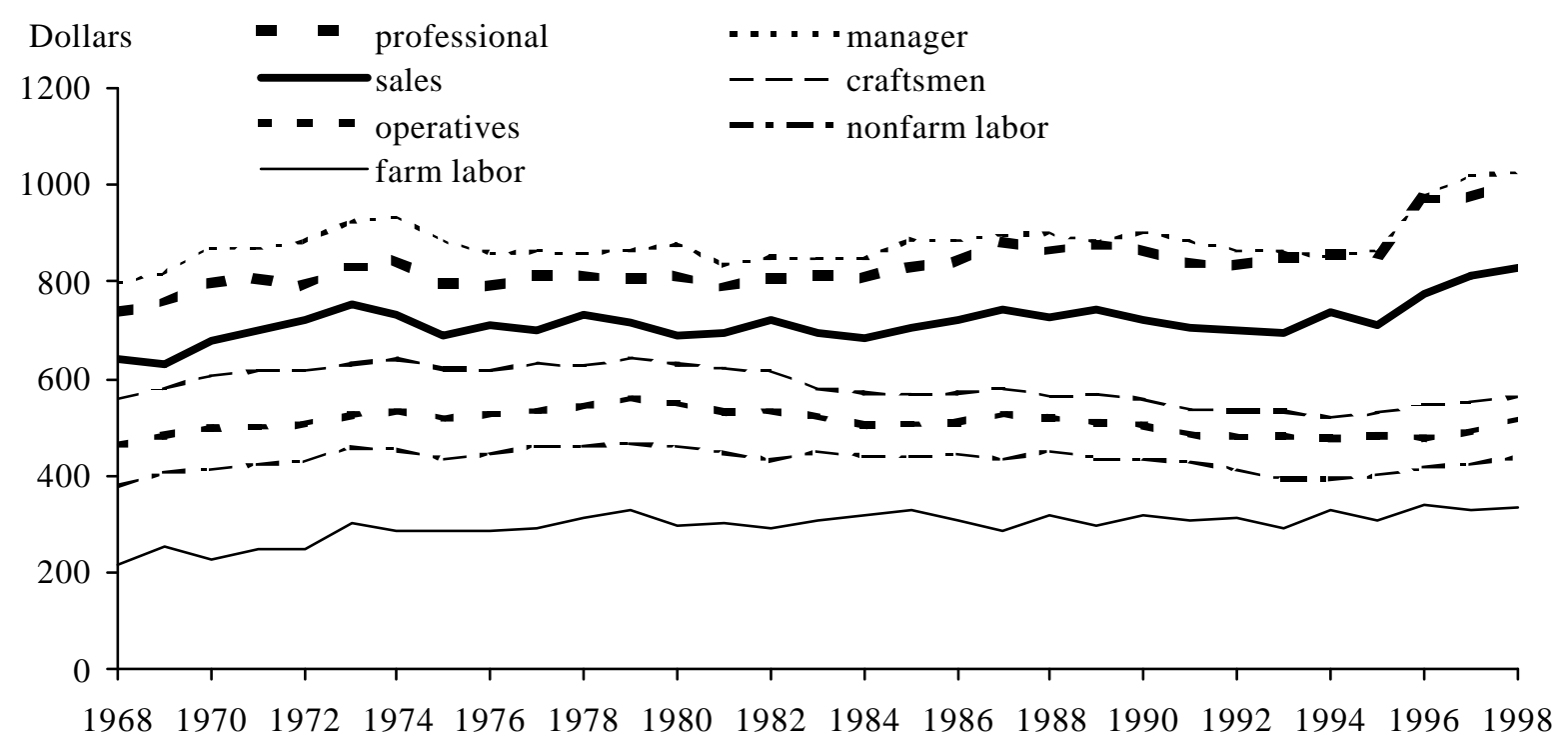

Source: Calculations by authors from 1968-1998 March Demographic Supplement to the CPS. 
Figure 5: Black-White Wage Gap 1968-1998

All Male Workers

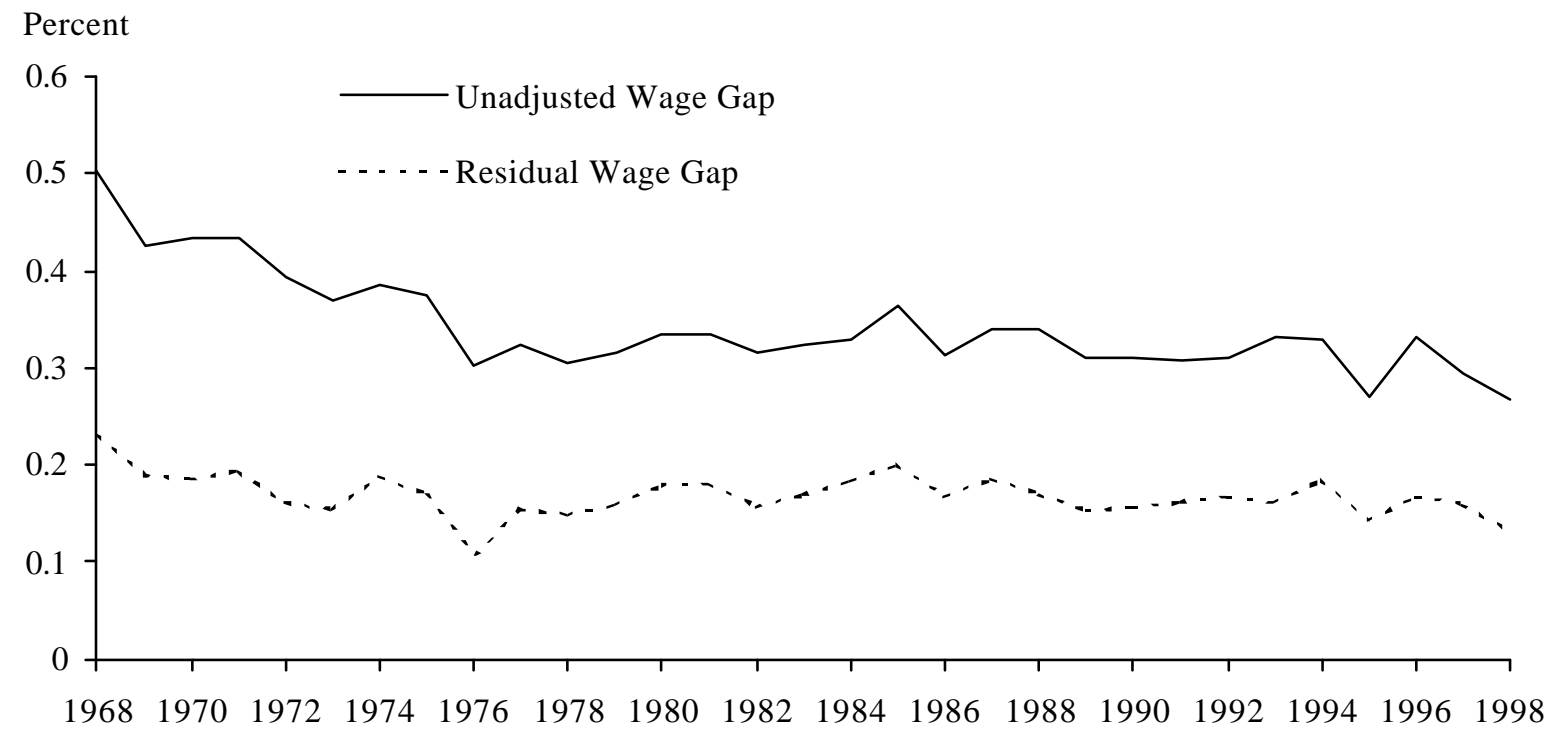

Figure 6: Black White Wage Gap 1968-1998

Male Workers With Less Than 10 Years Experience

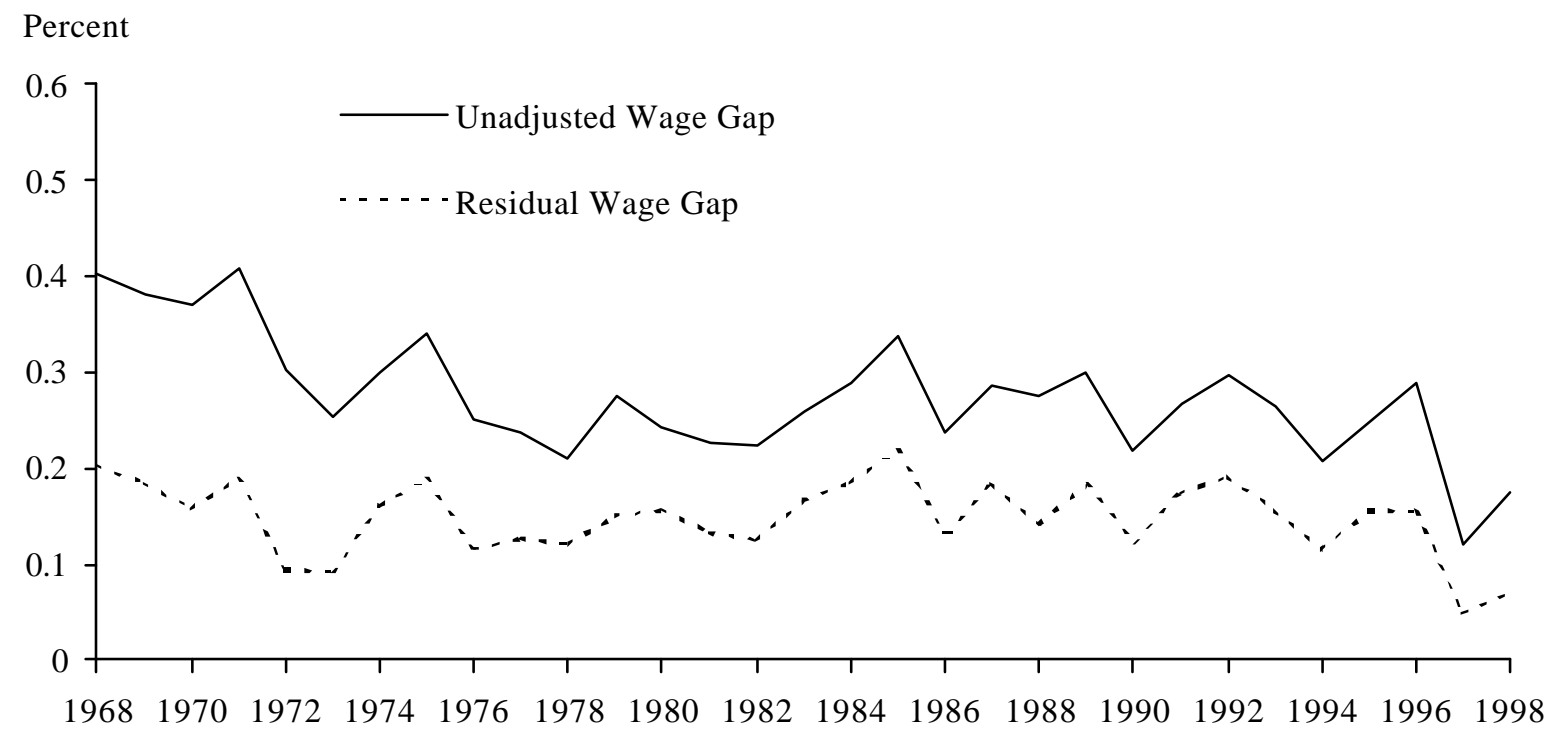

Source: Calculations by authors from 1968-1998 March Demographic Supplement to the CPS. 
Figure 7: Wage Dispersion Among College Graduates 1968-1998

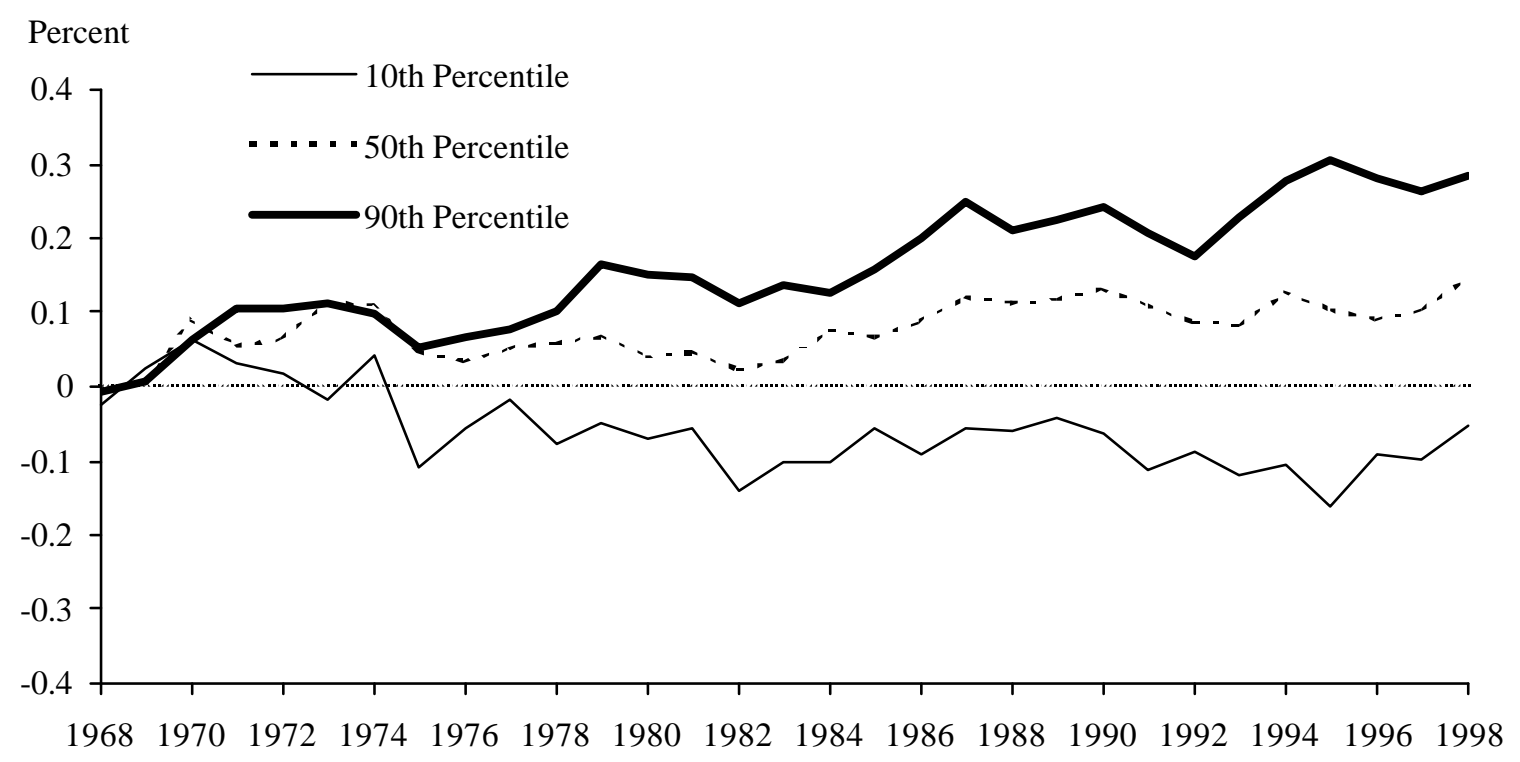

Figure 8: Wage Dispersion Among High School Graduates 1968-1998

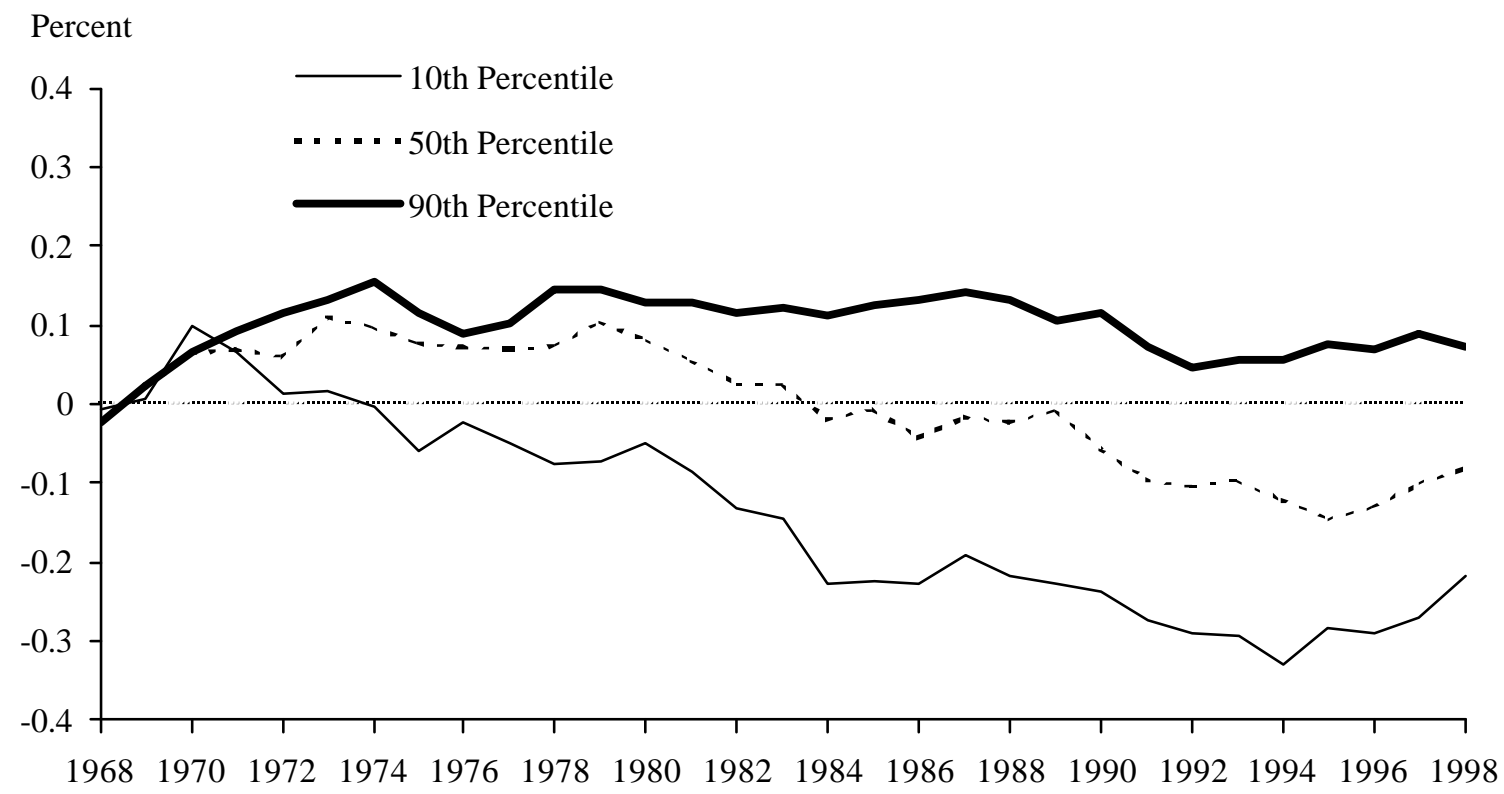

Source: Calculations by authors from 1968-1998 March Demographic Supplement to the CPS. 
Figure 9: Average Wage Growth by Percentile and Year

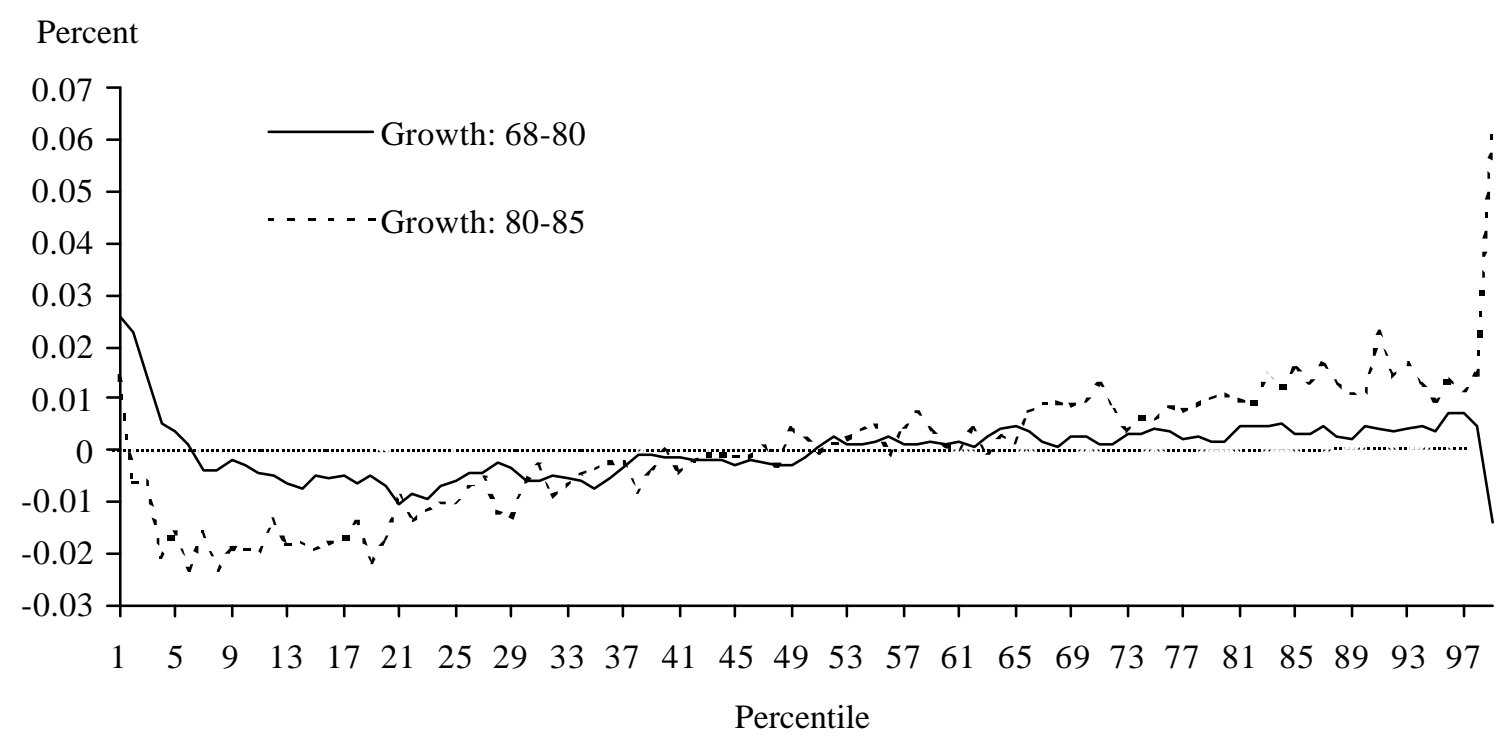

Figure 10: Average Wage Growth by Percentile and Year

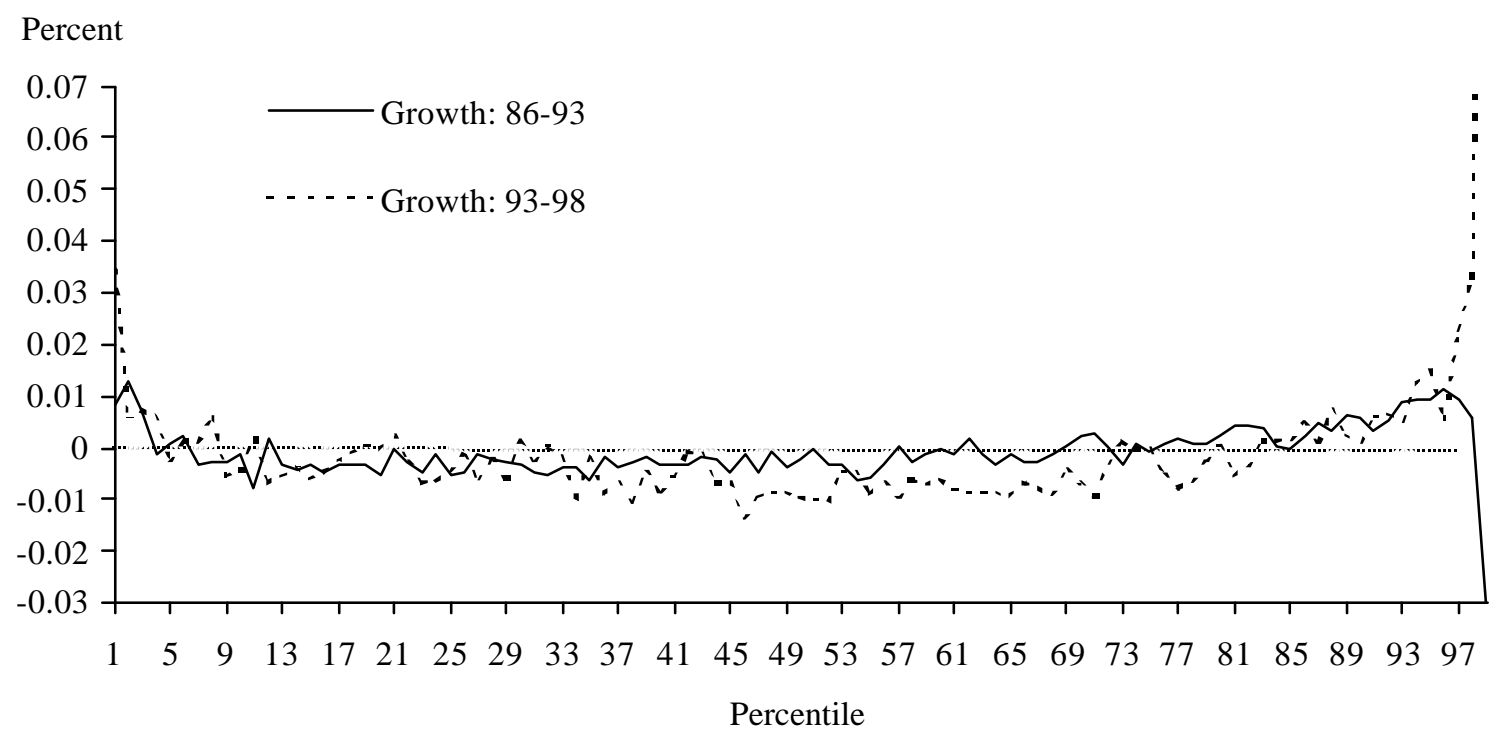

Source: Calculations by authors from 1968-1998 March Demographic Supplement to the CPS. 